\title{
Association Between Pain during Intracanal Diode Laser Application and Demographic and Preoperative Factors
}

\author{
Ezgi Doğanay Y1ldız ${ }^{1}$, Hakan Arslan ${ }^{2}$, Ertuğrul Karataş ${ }^{3}$ \\ ${ }^{1}$ Department of Endodontics, Faculty of Dentistry, Bursa Uludağ University, Bursa, Turkey \\ ${ }^{2}$ Department of Endodontics, Faculty of Dentistry, Health Sciences University, İstanbul, Turkey \\ ${ }^{3}$ Department of Endodontics, Faculty of Dentistry, Ataturk University, Erzurum Turkey \\ Received: 06 April 2020, Accepted: 29 June 2020, Published online: 31 August 2020 \\ (C) Ordu University Institute of Health Sciences, Turkey, 2020
}

\begin{abstract}
Objective: The present study aimed to evaluate the association between pain during intracanal diode laser irradiation in mandibular molar teeth have symptomatic apical periodontitis and factors such as demographic and preoperative factors.

Methods: Fourteen patients who have mandibular molar teeth have symptomatic apical periodontitis were enrolled in this clinical study. All endodontic treatments were performed in one-visit. After final irrigation, root canals were irradiated using a $970 \pm 15 \mathrm{~nm}$ diode laser with a $14 \mathrm{~W}$ maximum power. Pain during laser application, postoperative pain levels at day 1,3,5,7 and 30 and postoperative percussion tenderness levels at day 7 on the visual analog scale were marked. Multiple lineer regression was used for constructing a predictive model for intraoperative pain $(\mathrm{P}=0.05)$.

Results: $11(78 \%)$ patients reported pain during intracanal diode laser application. Age, gender, tooth type (first molar or second molar), side of the tooth (left or right), preoperative palpation, pulp status, preoperative percussion and preoperative spontaneous pain did not predict intraoperative pain during intracanal diode laser application $(\mathrm{F}(8,5)=2.332, \mathrm{p}>.05)$.

Conclusion: Within the limitations of the present clinical trial, none of the factors predict intraoperative pain during intracanal diode laser application.
\end{abstract}

Key words: Diode laser, intracanal laser, symptomatic apical periodontitis

Suggested Citation: Doganay Yıldız E, Arslan H, Karataş E. Association Between Pain during Intracanal Diode Laser Application and Demographic and Preoperative Factors. Middle Black Sea Journal of Health Science, 2020; 6(2):190-195.

\section{Address for correspondence/reprints:}

Ezgi Doğanay Yıldız

Telephone number: +90.224.294 0053-71

ORCID-ID 0000-0003-4113-7794

E-mail: dtezgidoganay@gmail.com

DOI: $\quad 10.19127 / \mathrm{mbsjohs.715298}$

\section{Introduction}

Reasons of postoperative pain are complex. There are conflicting results about the effect of age, gender and systemic diseases on postoperative pain (Torabinejad et al., 1988; Glennon et al., 2004). However, it was reported that tooth type, initial root canal treatment or retreatment, anxiety and allergic situations are associated with postoperative pain (Shavit et al., 1984; Soukos et al., 2006). In addition, using medicine, such as corticosteroid, preoperatively or postoperatively affects the postoperative pain (Torabinejad et al., 1988). Preoperative factors such 
as swelling, pain, percussion tenderness, sinus tract, periapical lesion have significant effect on postoperative pain (Torabinejad et al., 1988; Walton and Fouad, 1992; Glennon et al., 2004). Missed canals, incomplete root canal preparation, root canal medicaments, over preparation, irrigation solutions, paper points, root canal medicaments, apical debris and microorganism extrusion are operative reasons of postoperative pain (Alves Vde, 2010). Another factor affects the postoperative pain is experience of the clinician (Walton and Fouad, 1992). Although postoperative pain is a common subject in endodontics, intraoperative pain especially during laser application is not frequently studied subject.

One of the methods to control the pain and inflammation related to endodontic treatment procedures is improving of cleaning of the root canal system mechanically and chemically (Soukos et al., 2006; Garcez et al., 2007; Siqueira and Rocas, 2008). One of the methods for decontamination of root canals is using lasers, which aims to enhance the limited effect of traditional techniques caused by the anatomic three-dimensional complex structure of the root canal system. For this aim, various laser systems have been used and one of them is diode laser. Since diode laser does not damage the dental hard tissues, it is effective on microorganisms in dentinal tubules (de Souza et al., 2008). A study showed that diode laser irradiation provides has high bactericidal effect against Enterococcus faecalis, the bacteria that are the most difficult to eliminate, even at the $1000-\mu \mathrm{m}$ depth of dentine (Schulte-Lunzum et al., 2017).

Although the intracanal diode laser application has antibacterial effects in the root canal, it may have effect on postoperative or intraoperative pain. Thus, the present study aimed to evaluate the association between pain during intracanal diode laser irradiation in mandibular molar teeth have symptomatic apical periodontitis and factors such as demographic and preoperative factors.

\section{Methods}

A quasi experimental design was conducted. Ethics committee approval was received from Clinical Research Ethics Committee of Ataturk University (no. 05-2014).

Inclusion criteria were having mandibular molar tooth has symptomatic apical periodontitis, having preoperative pain and preoperative percussion tenderness greater than 60 on a $100 \mathrm{~mm}$ - Visual Analog Scale (VAS).

Exclusion criteria were presence of periapical radiolucency, severe periodontal disease, preoperative swelling or sinus tract. Patients who had used analgesics within the last 3 days were also not included.

According to these criteria, 14 patients were included in the present study. All root canal treatments were performed by one operator in onevisit under rubber-dam isolation. Root canal instrumentation was performed using Reciproc instruments (VDW, Munich, Germany). During instrumentation, $1 \%$ sodium hypochlorite was used between 3 in-and-out pecking motions. For final irrigation procedure, $5 \mathrm{~mL}$ of $1 \% \mathrm{NaOCl}$ for 1 minute and $5 \mathrm{~mL}$ of $5 \%$ EDTA for 1 minute was used. After final irrigation, root canals were dried using paper points. For intracanal diode laser application, a $970 \pm$ $15 \mathrm{~nm}$ diode laser with a $14 \mathrm{~W}$ maximum power (SIROLaser Xtend; Sirona Dental Systems GmbH, Bensheim, Germany) was used. A $200 \mu \mathrm{m}$ optical tip was placed into the apical third of the root canal. Then, it was activated and up-down motion was applied up to $1 \mathrm{~mm}$ from the working length. The laser application was performed at $2 \mathrm{~W}$ using the continuous wave mode and distilled water was applied during laser application in this group. Totally, irradiation time was $60 \mathrm{~s}$ for each tooth. After this procedure, root canals were dried using paper points, and root canal filling was completed using guttapercha cones and a resin-based selaer (2 seal; VDW, Munich, Germany). Access cavities were restored using nanohybrid composite resin (3M-ESPE, St. Paul, MN, USA). 400 mg ibuprofen (Brufen; Abbott, Latina, Italy) was prescribed to the patients and the patients were informed to note the analgesic intake.

Patients were marked pain during laser application on VAS. A form was given to the patients in order to record their postoperative pain level at day 1, 3, 5, 7 and 30. Patients were recalled after one week in order to apply percussion test. Patients recorded postoperative percussion tenderness at this visit. The scores of the patients on VAS were measured using a ruler and recorded in millimeters.

\section{Statistical Analysis}

For all the statistical analyses, IBM Statistical Package for the Social Sciences version 20 (IBM SPSS Inc, Chicago, IL, USA) for Windows was used. Multiple lineer regression was used for constructing a predictive model for intraoperative pain $(\mathrm{P}=0.05)$.

Assumptions for lineer regression test were as follows; a continuous dependent variable, at leaset two or more independent variables, independence of residuals, linearity, homoscedasticity, multicollinearity and absence of outliers.

The primary output variable was intraoperative pain during intracanal diode laser application. 
For multiple lineer regression analysis, postoperative pain was recorded as "present" if the patient scored his/her pain more than 30 on VAS on any day; postoperative pain was recorded as "absent" if the patient scored his/her pain less than 30 on VAS on every day postoperatively or the patient used analgesic postoperatively.

The data of gender (male/female), pulpal status (vital or nonvital) and preoperative palpation (absent/present) were recorded as nominal data.

The data of preoperative/postoperative pain and preoperative/postoperative percussion tenderness were used as scale data $(0-100 \mathrm{~mm})$ to compare to each other. The highest postoperative pain value was selected as postoperative pain. Kolmogorov-Smirnov test was used as normality test. Since the data was distributed normally and there was no extreme data, paired-samples t test was used compare preoperative and postoperative pain data, preoperative/postoperative percussion data $(\mathrm{P}=$ $0.05)$.

\section{Results}

14 patients were enrolled in the present study. Their age range was between 18 and 30 years. 7 female $(50 \%)$ and 7 male $(50 \%)$ patients were enrolled. 6 teeth were left first molar, 2 teeth were left second molar and 6 teeth were right first molar. Age, gender and tooth number data are summarized in Table $1.8(57.1 \%)$ of treated teeth were vital and 6 $(42.9 \%)$ of treated teeth were nonvital.

Table 1. Demographic data of the patients

\begin{tabular}{lc}
\hline & $\begin{array}{c}\text { Intracanal Diode Laser } \\
\text { Application }\end{array}$ \\
\hline Age & $23.93 \pm 3.81$ \\
Gender & \\
Male & 7 \\
Female & 7 \\
Tooth Number & \\
$\quad$ Left first molar & 6 \\
Left second molar & 2 \\
Right first molar & 6 \\
Right second & 0 \\
molar & \\
\hline
\end{tabular}

Pain and percussion tenderness data (preoperative and postoperative) are in Table 2. According to the paired-samples $\mathrm{t}$ test, there were significant differences between preoperative postoperative pain, and preoperative and postoperative percussion tenderness $(\mathrm{P}<0.05)$.
Table 2. Preoperative and postoperative pain and percussion tenderness data (mean \pm standard deviation) (The highest postoperative pain value was selected as postoperative pain)

\begin{tabular}{lcc} 
& $\begin{array}{c}\text { Measurements on } \\
\text { VAS (in } \\
\text { millimetres) }\end{array}$ & P value \\
\hline Preoperative Pain & $85.64 \pm 10.63$ & 0.00 \\
Postoperative Pain & $34.64 \pm 27.07$ & \\
\hline $\begin{array}{l}\text { Preoperative Percussion } \\
\text { Tenderness } \\
\begin{array}{l}\text { Postoperative } \\
\text { Percussion Tenderness }\end{array}\end{array}$ & $78.50 \pm 10.93$ & 0.00 \\
\hline
\end{tabular}

6 patients in intracanal diode laser application group used analgesic postoperatively. 11 (78 \%) patients reported pain during intracanal diode laser application.

No patient was referred for an unscheduled appointment. None of the patients had postoperative palpation tenderness, swelling and sinus tract.

\section{Intraoperative pain}

R2 for the overall model was $78.9 \%$ with an adjusted R2 of 45\%, a strong effect size. Age, gender, tooth type (first molar or second molar), side of the tooth (left or right), preoperative palpation, pulp status, preoperative percussion and preoperative spontaneous pain did not predict intraoperative pain. $(\mathrm{F}(8,5)=2.332, \mathrm{p}>.05)$.

\section{Discussion}

Intracanal diode laser application is used for removal of smear layer (Saghiri et al., 2012; Lagemann et al., 2014; Sohrabi et al., 2016), root canal disinfection (Mehrvarzfar et al., 2011; Beer et al., 2012; Bago et al., 2013; Neelakantan et al., 2015; Sohrabi et al., 2016) and increase in bond strength of sealers (Moura-Netto et al., 2012; Das et al., 2013; Maenosono et al., 2015). However, according to our literature search, there are not many in vivo studies about intracanal diode laser application (Morsy et al., 2018; Genc Sen and Kaya, 2019) and there is no study relating to the association between pain during intracanal diode laser application factors such as demographic, preoperative and postoperative factors. Therefore, the present study aimed to evaluate the association between pain during intracanal diode laser application in mandibular molar teeth have symptomatic apical periodontitis and factors such as demographic, preoperative factors. The results of the present clinical study showed that none of the factors predict intraoperative pain. 
In a study by Yoo et al. (2014), the influence of a 1440-nm Nd:YAG laser on relieving pain and found that the 1440-nm Nd:YAG laser irradiation provided significantly decrease in pain on percussion. Morsy et al. (2018) reported that diode laser might be a useful in order to reduce of postoperative pain after endodontic treatment in teeth with necrotic pulps and chronic periapical periodontitis. Genc Sen and Kaya (2019) reported that diode laser application provided less postoperative pain than control group and improved postoperative comfort after endodontic retreatment.

Murillo-Benitez et al. (2020) investigated correlation between intraoperative pain and some factors such as age, gender, and anxiety during endodontic treatment. Murillo-Benitez et al. (2020) reported that there was no correlation between intraoperative pain and age; and between intraoperative pain and gender; there was correlation between preoperative pain and intraoperative pain. Murillo-Benitez et al. (2020) did not irradiated root canals using laser. Although a direct comparison is not possible, it can be claimed that the results related to age and gender are in accordance with the results of the present study, but the result related to preoperative pain is not. Yücel et al. (2018) and Kayaoğlu et al. (2016) reported that age is a significant factor for intraoperative pain, but gender is not. While the result related to gender is in accordance with the results of the present study, the result related to age is not, although a direct comparison is not possible, again.

Morsy et al. (2018) used diode laser at $1.2 \mathrm{~W}$ power. Genc Sen and Kaya (2019) used diode laser at $1 \mathrm{~W}$ power. In the present clinical study, diode laser was used at 2 Was suggested by the manufacturer.

Laser energy can be used with the continuous wave mode or the pulsed mode. The continuous wave mode can cause heat increase in tissues. Therefore, air- or water-cooling is required when irradiation was done using the continuous wave mode (Coluzzi, 2000). In the present clinical trial, the intracanal laser application was performed using the continuous wave mode and distilled water-cooling was applied during irradiation in order to eliminate the risk of thermal damage as much as possible.

\section{Conclusion}

During intracanal laser applications, $78 \%$ of the patients reported pain during intracanal laser application. Within the limitations of the present clinical trial, none of the factors predict intraoperative pain during intracanal diode laser application.

\section{Acknowledgements}

The data of the present study is a part of the thesis by Ezgi Doğanay Yıldız.

Ethics Committee Approval: Ethics committee approval was received from the Research Ethics Committee of Ataturk University (Decision No. 052014).

Peer-review: Externally peer-reviewed.

Author Contributions: Concept- E.D.Y., H.A., Design- E.D.Y., H.A., Supervision- E.D.Y., H.A., Literature Review- E.D.Y., H.A., Writing- E.D.Y., H.A., E.K., Critical Review- E.D.Y., H.A., E.K.

Conflict of Interest: No conflict of interest was declared by the authors.

Financial Disclosure: Supported in part by the TUBITAK Research Fund (no. 114S910).

\section{References}

Alves Vde O. Endodontic flare-ups: a prospective study. Oral Surg Oral Med Oral Pathol Oral Radiol Endod 2010;110(5): e68-72.

Bago I, Plecko V, Gabric Panduric D, Schauperl Z, Baraba A, Anic I. Antimicrobial efficacy of a high-power diode laser, photo-activated disinfection, conventional and sonic activated irrigation during root canal treatment. Int Endod $\mathbf{J}$ 2013;46(4): 339-347.

Beer F, Buchmair A, Wernisch J, Georgopoulos A, Moritz A. Comparison of two diode lasers on bactericidity in root canals--an in vitro study. Lasers Med Sci 2012;27(2): 361-364.

Coluzzi DJ. An overview of laser wavelengths used in dentistry. Dent Clin North Am 2000;44(4): 753765.

Das M, Kumar GA, Ramesh S, Garapati S, Sharma D. An in vitro evaluation of microtensile bond strength of resin-based sealer with dentin treated with diode and Nd:YAG laser. J Contemp Dent Pract 2013;14(2): 183-187.

de Souza EB, Cai S, Simionato MR, Lage-Marques JL. High-power diode laser in the disinfection in depth of the root canal dentin. Oral Surg Oral Med Oral Pathol Oral Radiol Endod 2008;106(1): e6872. 
Garcez AS, Ribeiro MS, Tegos GP, Nunez SC, Jorge AO, Hamblin MR. Antimicrobial photodynamic therapy combined with conventional endodontic treatment to eliminate root canal biofilm infection. Lasers Surg Med 2007;39(1): 59-66.

Genc Sen O, Kaya M. Effect of Root Canal Disinfection with a Diode Laser on Postoperative Pain After Endodontic Retreatment. Photobiomodul Photomed Laser Surg 2019;37(2): 85-90.

Glennon JP, Ng YL, Setchell DJ, Gulabivala K. Prevalence of and factors affecting postpreparation pain in patients undergoing twovisit root canal treatment. Int Endod J 2004;37(1): 29-37.

Kayaoglu G, Gurel M, Saricam E, Ilhan MN, Ilk O. Predictive Model of Intraoperative Pain during Endodontic Treatment: Prospective Observational Clinical Study. J Endod 2016;42(1): 36-41.

Lagemann M, George R, Chai L, Walsh LJ. Activation of ethylenediaminetetraacetic acid by a $940 \mathrm{~nm}$ diode laser for enhanced removal of smear layer. Aust Endod J 2014;40(2): 72-75.

Maenosono RM, Bim Junior O, Duarte MA, PalmaDibb RG, Wang L, Ishikiriama SK. Diode laser irradiation increases microtensile bond strength of dentin. Braz Oral Res 2015;29: 1-5.

Mehrvarzfar P, Saghiri MA, Asatourian A et al. Additive effect of a diode laser on the antibacterial activity of $2.5 \% \mathrm{NaOCl}, 2 \% \mathrm{CHX}$ and MTAD against Enterococcus faecalis contaminating root canals: an in vitro study. J Oral Sci 2011;53(3): 355-360.

Morsy DA, Negm M, Diab A, Ahmed G. Postoperative pain and antibacterial effect of 980 $\mathrm{nm}$ diode laser versus conventional endodontic treatment in necrotic teeth with chronic periapical lesions: A randomized control trial. F1000Res 2018;7: 1795.

Moura-Netto C, Palo RM, Camargo SE, Jent C, Leonardo Rde T, Marques MM. Influence of prior 810-nm-diode intracanal laser irradiation on hydrophilic resin-based sealer obturation. Braz Oral Res 2012;26(4): 323-329.
Murillo-Benitez M, Martin-Gonzalez J, JimenezSanchez MC, Cabanillas-Balsera D, VelascoOrtega E, Segura-Egea JJ. Association between dental anxiety and intraoperative pain during root canal treatment: a cross-sectional study. Int Endod J 2020;53(4): 447-454.

Neelakantan P, Cheng CQ, Mohanraj R, Sriraman P, Subbarao C, Sharma S. Antibiofilm activity of three irrigation protocols activated by ultrasonic, diode laser or Er:YAG laser in vitro. Int Endod $\mathbf{J}$ 2015;48(6): 602-610.

Saghiri MA, Asgar K, Gutmann JL et al. Effect of laser irradiation on root canal walls after final irrigation with 17\% EDTA or BioPure MTAD: Xray diffraction and SEM analysis. Quintessence Int 2012;43(10): e127-134.

Schulte-Lunzum R, Gutknecht N, Conrads G, Franzen R. The Impact of a $940 \mathrm{~nm}$ Diode Laser with Radial Firing Tip and Bare End Fiber Tip on Enterococcus faecalis in the Root Canal Wall Dentin of Bovine Teeth: An In Vitro Study. Photomed Laser Surg 2017;35(7): 357-363.

Shavit Y, Lewis JW, Terman GW, Gale RP, Liebeskind JC. Opioid peptides mediate the suppressive effect of stress on natural killer cell cytotoxicity. Science 1984;223(4632): 188-190.

Siqueira JF, Jr., Rocas IN. Clinical implications and microbiology of bacterial persistence after treatment procedures. J Endod 2008;34(11): 1291$1301 \mathrm{e} 1293$.

Sohrabi K, Sooratgar A, Zolfagharnasab K, Kharazifard MJ, Afkhami F. Antibacterial Activity of Diode Laser and Sodium Hypochlorite in Enterococcus Faecalis-Contaminated Root Canals. Iran Endod J 2016;11(1): 8-12.

Soukos NS, Chen PS, Morris JT et al. Photodynamic therapy for endodontic disinfection. J Endod 2006;32(10): 979-984.

Torabinejad M, Kettering JD, McGraw JC, Cummings RR, Dwyer TG, Tobias TS. Factors associated with endodontic interappointment emergencies of teeth with necrotic pulps. J Endod 1988;14(5): 261-266.

Walton R, Fouad A. Endodontic interappointment flare-ups: a prospective study of incidence and related factors. J Endod 1992;18(4): 172-177. 
Yoo YJ, Shon WJ, Baek SH, Kang MK, Kim HC, Lee W. Effect of 1440-nanometer neodymium:yttrium-aluminum-garnet laser irradiation on pain and neuropeptide reduction: a randomized prospective clinical trial. J Endod 2014;40(1): 28-32.

Yucel O, Ekici MA, Ilk O, Ilhan MN, Kayaoglu G. Predicting intraoperative pain in emergency endodontic patients: clinical study. Braz Oral Res 2018;32: e38. 